\title{
Ties that Bind: The Link between Functions of Public Sector Manager in Tanzania and Luther Gulick's Notes on The Theory of Organization
}

Ramadhani MARIJANI,

Tanzania Public Service College, Tabora, Tanzania

ramadhani.marijani@tpsc.go.tz

\begin{abstract}
This paper reflects Gulick's notes on the theory of organization in the context of Public Sector Manager's work milieu in Tanzania. Using the Performance Improvement Model (PIM) as the proxy the paper instantiates the POSDCORB by drawing the parallels between the POSDCORB mnemonic and PIM and therefore corroborates Gulick's summation. We argue that in order to apply the classic theory of organization in today's public administration an attempt should be made to view organization theory from a design perspective. The paper recommends that more research should be done to instantiate POSDCORB and contributes to the corpus knowledge of public administration discipline.
\end{abstract}

Keywords: Theory of Organization; Performance Improvement Model; POSDCORB

JEL Classification: M1, M10, L32.

\section{Introduction}

With the coming of the industrial revolution in the $19^{\text {th }}$ century, several attempts were made to develop the principles of organization to meet the requirements of the emerging industry (Rao, 2012:82). Among such notably attempts includes the works of Frederick Winslow Taylor and Henry Fayol who propounded the well known classical organization theory.

Other scholars contributed to the conceptualization of the theory by developing theories of keeping organization efficiency and increased productivity. As a result, some theorists synthesized the organizational and management theories to be applicable to public organizations (ibid). Notably among such writers, Luther Gulick and Lyndall Urwick deserve special credits, their edited collection "The papers on the Science of Administration (1937) " is 
considered to be a fort sumter in the development of the science of administration.

Their 1937's collection included the essay by Gulick entitled, "Notes on the Theory of Organization" originally written when he was a member of President Franklin D. Roosevelt's committee on Administrative Management popularly known as the 'Brownlow Commission' tasked with the reorganization of the federal executive branch in the United States. In "Notes" Gulick (1937) invented the famous mnemonic POSDCORB to explain the key responsibities of a public manager. POSDCORB entails seven key functions: planning, organizing, staffing, directing, coordinating, reporting, and budgeting (Espy and Guy 2017:1993; Fairholm 2004:580). Over time, the essay stood by far the most sophisticated comprehensive understanding of the problem of organizational design and general public management by any scholar of that era (Hammond, 1990:143).

Of late, the meaning and applicability of the POSDCORB is still the same, thus defined in the contemporarily context, it would be "planning, operating, staffing, deciding, cooperating, reporting, and budgeting" (Stillman, 2015; Yang 2015).The words keep on slightly changing, but by and large the tasks remain the same.

To date, the reflections on POSDCORB elements should be done in a particular context, as the public sector products, services and programs differ from one another. Thus even though the same fundamental elements will be used to deliver certain products or services, the emphasis will vary according to the context (Espy and Guy, 2017:194).

It is on the basis of the above backdrop that this paper attempts to reflect on Gulick's notes on the Theory of Organization in the context of Public Sector manager's work milieu in Tanzania where POSDCORB is viewed as the institutional device for delivering public services. This is done to extend Luther Gulick's organizational patterns as Chalekian (2013) eloquently posited that patterns are a way to integrate complex theories and practices.

The paper is organized as described below, after introduction section there comes the conceptual framework which presents Luther Gulick's approach to organization. Next is the section that links Gulick's design with Performance Improvement Model which attempts to explain the instances of POSDCORB in the Tanzania public sector. It is followed by the section that presents the revisionist view of relevance of Gulick and classical management for today's public administration. Finally, the paper ends with conclusion and proposal for further research. 


\section{Conceptual Framework: Luther Gulick's approach to organization}

This section re-visits the core patterns of administration as the patterns allow for purposeful actions (Chalekian, 2013:1). POSDCORB which stand for: Planning, Directing, Coordinating, Reporting, and Budgeting was firstly coined by Luther Gulick, a highly respected scholar and administrator whose nickname came to be the "Dean of American Public Administration" (Chalekian, 2013:1; Espy and Guy, 2017:193).

In his lifetime Gulick coined the word and associated elements in an essay entitled "Notes on the Theory of Organization (1937).Ever since, the document has been widely read and applicability of the POSDORB has been tested and discussed widely to the extent that it has been suggested as a framework (Raadschelders and Lee, 2011; Chalekian, 2013; Graham and Hays, 1986).

Gulick's contributions which were reformatory and forward-looking were largely influenced by his use of design science (2013:3).Since organization was conceived as mainly designing process. Lack of design was therefore illogical, cruel, wasteful and inefficient (Prasad et al, 2010:84). This is because it is through design structures are developed, staffing facilitated and employees rightly compensated. Thus one of the notable features in the writings of Gulick is the central position attached to the structure of administration, having stressed the importance of the structure in designing process.Gulick delved much on the discovery of principles to be used in designing the structures (ibid). In working out the aforesaid principles, Gulick was largely influenced by Henry Fayol's fourteen basic elements of administration to the extent that he translated his works from French to English (Chalekian, 2013:4).

Fayol proposed a number of descriptions of administration member tasks. They include division of work or specialization, bases of departmental organization, coordination through hierarchy, deliberate coordination, coordination through committees, decentralization, unity of command, staff and line, delegation and span of control (Prasad etal.2010). Later on by integrating Fayol's fourteen principles Gulick encoded and encapsulated CO (for "coordination" or "control"), turned "command "to D (for "directing"), and combined Fayol's work with " accounting and statistics" and "financial problem" into B (for "budgeting"). Moreover, the codification included Planning, Organizing, Staffing, Directing, Coordinating, Reporting and Budgeting, resulting to his POSDCORB mnemonic which has been used to abbreviate the list of management functions (Chalekian, 2013:4).

In reflecting the current role of public sector manager, Paul Chalekian (2013) poses an intriguing question that "could POSDCORB still be considered a 
framework?" .The answer is yes, as posited by Graham and Hays (1986), Stillman (1991) and Chalekian (2013). Moreover, Agranoff and McGuire (2011) further confirm that to date there is no any other agreed-up on set of functional tasks exists that is akin to POSDCORB.

There is the paucity of the discussion of public administration frameworks in the literature as compared to policy studies and sub-field of policy implementation where there are numerous frameworks (Chalekian, 2013:5).The above claim still reverberates to date, as Urwick (1947) pointed the administrative organization is still an unexplored field and there are many unknown factors for a fuller understanding. Therefore, the proposed principles form a framework of thought and arrangement of ideas which would assist others to synthesize out of their experiences.

To augur well with our previous thesis, the subsequent section attempts to link Gulick's design with the Tanzania Public Service Performance Improvement Model and to explain the instances of POSDCORB in the public sector.

\section{The link between Gulick's design and the Tanzania Public Service Performance Improvement Model (PIM)}

This section attempts to tailor Gulick's attempts to simplify public administration by reflecting on the current role of public sector manager in Tanzania. This is done to connect the academic study of POSDCORB with experience of practitioners in the field to realize the practical experience of public administration education (Blumberg, 1981).

Over the years, the global political socio-economical, technological, environmental and legal situation has been changing at unprecedented pace necessitating the public sector organizations to face heightened challenges caused by fast changing internal and domestic environments. To mention but a few, the changes include; the development in information communication and technology (ICTs), the need for results oriented, the pressure for transparency and accountability, budget limitations and cuts and the pressure from the knowledgeable and informed consumers.

To address the aforementioned challenges, public sector organizations need to have in place effective performance management systems to guarantee high performance results from individual, teams and entire organizations. Since 1961, the Tanzanian Public Service underwent numerous reforms at different times in the country's post-independence history (Lukumayi, 2006:29). This paper specifically focuses on the Public Service Reform Programme (PSRP) basing chiefly on phase I of the reforms under PSRP which was implemented from 2000 
to 2007 and was dedicated to the "Installation of Performance Management Systems (PMS)" in the Public Sector.

Across the globe and Africa in particular, public service has adopted different approaches to performance management. In Tanzania Performance Management System (PMS) is implemented through the Performance Improvement Model (PMI) a home grown tool officially accepted as a tool for installing PMS in the Tanzania Public Service. Through the Public Service Management and Employment Policy (PSMEP) of 1999 as revised in 2008 which calls for performance and results oriented management philosophy in the public service and Public Service Act number 8 of 2002 as amended in 2007 which provides enabling legal framework to manage performance in the public service. Performance Management System (PMS) was institutionalized in the public service.

Performance Improvement Model (PIM) is a four stage interlinked process comprised of a series of integrated tools, approaches and components for planning, implementation, monitoring and evaluation, and performances reviews (TPSC, 2018). PIM has eight (8) inter-related and interdependent tools as indicated in the diagram below;

Figure 1: Performance Improvement Model - PIM

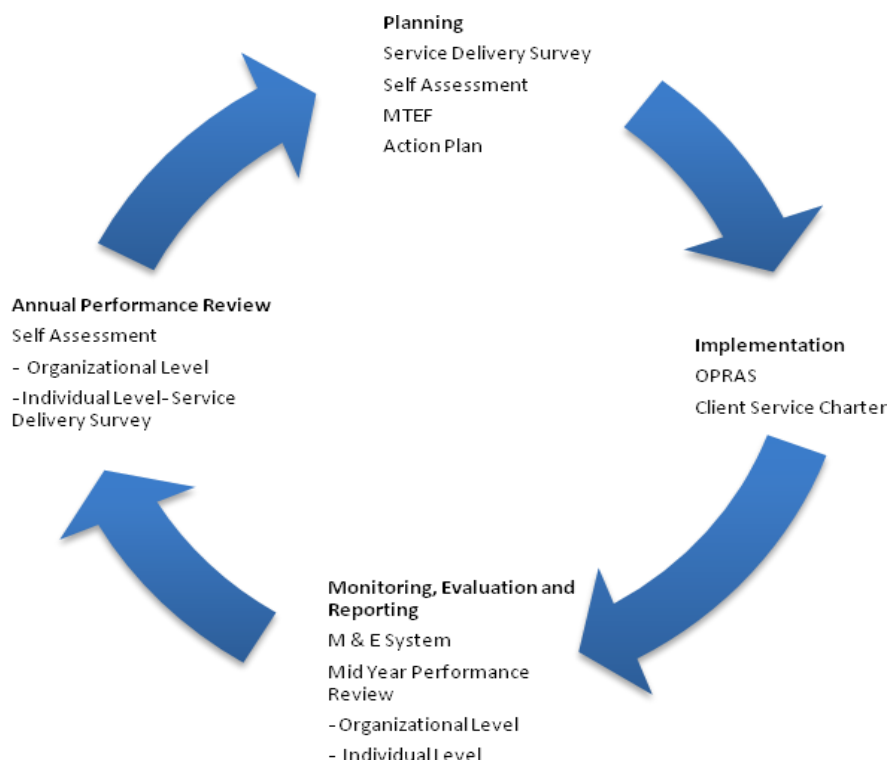

Source: URT (2000) Public Service Reform Programme 2000-2001 
The above model reflects the key elements of POSDCORB which are routinely used by public sector manager in Tanzania, as all the elements of POSDCORB are fully integrated into the model. Thus, fully Implementation of the model requires staffing, coordinating, budgeting, monitoring and evaluation and reporting to key stakeholders.

\section{Planning: That Public Sector Manager must Plan}

Martin (1987:299) argues that Gulick's POSDCORB was offered as the rejoinder to the question, what is the work of the Chief Executive? What does he/she do? At the initial stage of PIM planning process is preceded by Service Delivery Survey (SDS), which provides information on the level of service provided to the public and feed into strategic planning process. The information from SDS is corroborated with the results of self assessment - which generates information on areas for improvement and benchmarking and collectively forms inputs for strategic planning process.

The information from above exercises is then used to develop "Medium Term Strategic Plans" - which chart the direction of the institution. To instantiate the strategic plan, the Medium-Term-Expenditure Framework (MTEF) which is a tool for opertationalising the plan is developed, eventually the 'Action plans' which set out what is to be done during the year, when and by who, bring the planning process to an end in Tanzania Public Service. With Gulick (1937), planning is the inherent aspect of management process and therefore should be done systematically and in hierarchical order. The PIM clearly shows the steps and process of planning in the public service.

Table 1: Planning

\begin{tabular}{|c|c|}
\hline "Notes & The Performance Improvement Model \\
\hline $\begin{array}{c}\text { "Planning, that is working out in broad outline } \\
\text { the things that need to be done and the }\end{array}$ & Service Delivery Survey \\
methods for doing them to accomplish the & Self-Assessment \\
purpose set for the enterprise" & Medium Term Strategic Plans \\
(Gulick, 1937:13) & Medium Term Expenditure Framework (MTEF) \\
\hline
\end{tabular}

Source: Adopted from Espy and Guy (2017:196)

\section{Organizing: That Public Sector Manager must Organize Works}

To Gulick, 'organizing' was instrumental in ensuring 'coordination' or various activities, it was also a strategy for maintaining domestic tranquility for national survival (Martin, 1987:299).Organization is the basic element of any human endeavor which involves more than one person (Gullick, 1937).

Therefore, there must be clear allocation of tasks and a person who directs the execution of them (Espy and Guy, 2017:197). To accomplish 'organizing' process the Performance Improvement Model introduced the Open Performance 
Review and Appraisal System (OPRAS) which shows the individual contributions towards achieving the entire organization objectives and the 'Client Service Charters' which describes the services a client can expert from the public organizations and feedback channel to inform strategic planning.

Table 2: Organizing

\begin{tabular}{|c|c|}
\hline "Notes" & The Performance Improvement M odel \\
\hline "Organizing, that is the establishment of the & Open Performance Reviews and Appraisal \\
formal structure of authority through which & System (OPRAS) \\
work subdivisions are arranged, defined and \\
co-ordinate for the defined objectives" (Gulick, \\
$1937: 13$ )
\end{tabular}

Source: Adopted from Espy \& Guy (2017:197)

Staffing: That the Public Sector Manager should Ensure Placement, Training for Achieving Organizational Goals.

Urwick (1937) stresses the importance of interrelationship of organizational structure, staffing, roles and responsibilities and the need for specialization to ensure performance. With Gulick (1937), the purpose should inform the type of employees needed in an organization. Moreover, staffing is not only about hiring and firing and place to perform, it is also alignment of skills and needs of both the employees and organization (Espy and Guy, 2017:198). This distinction is clearly evident in the Performance Improvement Model through 'cascading 'of objectives in implementing OPRAS.

Table 3: Staffing

\begin{tabular}{|c|c|}
\hline "Notes" & The Performance Improvement Model \\
\hline "Staffing, that is the whole personnel function & Open Performance Reviews and Appraisal \\
of bringing in and training the staff and & System (OPRAS) \\
maintaining favorable condition work" & Cascading of objectives \\
(Gulick, 1937, p.13) & Performance Appraisal \\
\hline
\end{tabular}

Source: Adopted from Espy and Guy (2017:198)

\begin{abstract}
Directing: That Public Sector Manager must make Decisions, Issue Orders and Provide Leadership

Directing includes instructions to subordinates, impulsion, motivation, inspection or verification of subordinates' works (Martin, 1987:300). According to Fayol (1937), directing is the process of setting in motion the elements of a plan. Gulick (1937) conceived directing as an on going action which is contingent to the environment. Decision must therefore be made when the circumstance unfolds and evolve.
\end{abstract}


The decisions in the PIM model should reflect on the strategic plans with clear Key Performance Areas (KRAs) and an approval budget (MTEF) before implementation.

Table 4: Directing

\begin{tabular}{|c|c|}
\hline "Notes" & The PIM model \\
\hline "Directing, that is the continuous task of & Strategic Planning \\
making decision and embodying them ins & Medium Term Expenditure \\
specific and general orders and instructions & Frameworks \\
and serving as a leader of the enterprise" & Action Plans \\
(Gulick, 1937:13) & \\
\hline
\end{tabular}

Source: Adopted from Espy and Guy (2017:198)

\section{Coordination: That Public Sector Manager must Ensure Various Parts of Work are Related}

Improving coordination was the primary purpose for studying public administration (Martin, 1987:300). Coordination can be fostered with the use of a strict hierarchy system. Gulick (1937) viewed coordination within the context of an organization under the leadership of a single authority with defined purposes. In the contemporary literature coordination includes collaboration (Stillman, 2015). Coordination is included in all four phases of Performance Improvement Model which includes, planning, implementation, monitoring and evaluation and annual performance reviews to inform strategic plans.

Table 5: Coordinating

\begin{tabular}{|c|c|}
\hline "Notes" & The Performance Improvement Model \\
\hline "Coordinating (cooperating), that is the all & Planning \\
important duty of interrelating, the various \\
$\begin{array}{c}\text { parts of the work" } \\
\text { (Gulick, 1937:13) }\end{array}$ & Implementing \\
\hline
\end{tabular}

Source: Adopted from Espy and Guy (2017:200)

\section{Reporting: That Public Sector Managers must Keep Key Stakeholders/society Informed of the Impact of Policies}

Reporting to key stakeholders on administrative issues is an integral part of any good manager. Fayol (1937) viewed reporting as an element of control and accountability which instills a sense of responsibility for employees and confidence among manager and availing information for informal decisions. In the Performance Improvement Model reporting is done in twofold, first reporting is done during midyear reviews through monitoring and evaluation system which details the mid year performance at organizational and individual level. Second is done during annual performance review stage where equally the performance at organizational and individual level is done. Reporting is done 
with the view that general public is vital stakeholders in understanding the performance of public sector organizations.

Table 6: Reporting

\begin{tabular}{|c|c|}
\hline "Notes" & The Performance Improvement Model \\
\hline "Reporting, that keeping those to whom the & Monitoring, evaluation and reporting \\
executive is responsible informed as to what is & Annual Performance Review \\
going on, which thus includes keeping himself & Organizational level \\
and his subordinates informed through \\
records, research and inspection." \\
(Gulick, 1937:13)
\end{tabular}

Source: Adopted from Espy and Guy (2017:201)

\section{Budgeting: That Budget must be Planned and Public Sector Manager must maintain Financial Accountability}

Of all the laws whose execution is confided in the government, the one that exercise greatest influence over the general prosperity is the law of the budget (Martin 1987:301). Budget regulates the bases of administration and the costs that administration imposes in the country. The above statement indicates the central role of budgeting to the public administration.

The classical theorists view budgeting as an essential element of the work of public administration (Fayol, 137; Gulick, 1937). Both scholars embed budgeting in the context of planning, reporting and control.

Budgeting serves as a statement of priorities, and allocation of resources, a management control device and a tool for reporting and accountability. In the Performance Improvement Model budgeting is included right from phase one of the planning process just before implementation phase. After developing five year strategic plans and narrowing down to one year action plan. The Medium Term Expenditure Framework (MTEF) which is an operational tool is developed to support implementation of the plans.

Table 7: Budgeting

\begin{tabular}{|c|c|}
\hline "Notes" & The PIM model \\
\hline $\begin{array}{c}\text { "Budgeting, with all that goes with budgeting } \\
\text { in the form of fiscal planning, accounting and } \\
\text { control." } \\
\text { (Gulick, 1937:13) }\end{array}$ & $\begin{array}{c}\text { MTEF } \\
\text { Midoring and Evaluation } \\
\text { Mid Year Reviews }\end{array}$ \\
\hline
\end{tabular}

Source: Adopted from Espy and Guy (2017:201) 


\section{A revisionist view of relevance of Gulick and classical management for today's Public Administration}

"Principles" are universal truths subject to verification and science is by definition cumulative involving periods of paradigm shifts that occur when current theories fail to explain certain phenomena (Van der Waldt, 2017:23). The neo classical theorists urge that the universal validity appears to be absent as far as principles of administration are concerned (Prasad et al. 2010:89). Thus the Gulick and Urwick principles of organization were subject to torrent of severe criticisms. For example, some scholars labeled the principles as the "mere postulates of experienced men who have closely observed organization at work" Leonard D.White conceived the terms line, staff and auxiliary agencies, hierarchy, authority and centralization to be descriptive terms and no more. They are not considered to be rules.

The last straw on the attack was dropped by Herbert Simon (1965:20) who labeled the principles as homely proverbs, myths, slogans, largely a fatal defect of the current principles of administration that, like proverbs, they occur in pairs. For almost every principle one can find an equally plausible and acceptable contradictory principle. For example, one principle heralded that administrative efficiency increases by specialization but it is not clear weather area specialization is good or functional specialization.

Despite the criticisms, the vista to bring into focus is the enormous applicability of the Gulick's paper as it is too well known to explain here. Suffice is to admit that the paper stressed on the division of labor, functionalism and coordination of work and a concept of staff control including the famous POSDCORB formula around which most management texts reserved a page ever since (Riper, 1998; Chalekian, 2013:71).

As Van der Waldt (2017:23) correctly posited the applied social sciences like public administration should apply the existing themes to address a problem and generate new knowledge as the form of theory- testing. Critics should therefore re-read the "papers" more carefully, for it is neither as rigid nor dehumanized as heralded by the critics of classical management. Suffice also to appreciate that "papers" was the calling card not only for Fayol but also Follet and the Hawthorne studies to the scholarly audience (Chalekian, 2013: ).

In later years, scholars came to prove that some of the criticisms against POSDCORB were not even grounded (ibid). Thus even the adamant neoclassical theorist critics who faulted Gulick for lack of evidence, suggested that we should continue using the design. Notably among them is Herbert Simon who in 1997 
had revisionist view and suggested a second look at organizational theory from design perspectives (Simon, 1997).

By and large, the "papers" and specifically the elements of POSDCORB are still valid today eighty one years after the term was first corniced. As Espy and Guy (2017:203) observed, POSDCORB is at the heart of all government projects. Thus Gulick provided the components and it is up to scholars and practitioners to take action by developing, testing and advancing the theory (Chalekian 2013:24; Van der Waldt 2017:23).

\section{Conclusion, and Research implications}

The most important message of the Performance Improvement Model (PIM) and POSDCORB comparison is that, from process perspectives, the PIM and Gulick's POSDCORB have words in common. This confirms Espy and Guy (2017:203) position that POSDCORB is at the heart of all government projects. With the above similarities, PIM provides a means for teaching classics of public administration from design perspectives. This article argues that there is the paucity of studies undertaken to validate "classic" forms of management. Thus one contribution of this article is its attempt to view organizational theory from a design perspective through PIM. Moreover, we also recommend that more research should be done to instantiate the POSDCORB patterns in terms of how it is integrated with institutional analysis or policy implantation and how it can be decentralized so as to foster scientific rigor and continue to build the corpus of knowledge for public administrative discipline.

\section{References}

[1] Agranoff, R., \& McGuire, M. (2001).Big questions in public network management research, Journal of Public Administration Research and Theory. (11):295-326

[2] Blumberg, S.K. (1981).Seven decades of public administration: A tribute to Luther Gulick. Public Administration Review. 41(2)

[3] Chalekian, P. (2013).POSDCORB: Core Patterns of Administration, paper presented at the Proceedings of the $20^{\text {th }}$ Conference on Pattern Language of Programs, Plop' 13 (December, 2013), 20 pages.

[4] Fairholm, R.M. (2004). Different Perspectives on the Practice of Leadership. Public Administration Review. 64(5):577-590.

[5] Fayol, H. (1937). The Administrative theory in the state. In L. Gulick and Urwick (Eds.). Papers on the Science of Administration (pp.99-114). New York, NY: Institute of Public Administration. 
[6] Gulick, L.H. (1937). Notes on the theory of organization. In L. Gulick and Urwick (Eds.). Papers on the Science of Administration (pp. 3-35). New York, NY: Institute of Public Administration.

[7] Graham, C. and Hays, S.W. (1986). Managing the public organization. Washington, DC: Congressional Quarterly.

[8] Hammond, H.T.(1990).In defense of Luther Gulick's "Notes on the Theory of Organization." Public Administration. (68):143-173.

[9] Leigh, D.E. and Guy. E.M. (2017). May be it is Rocket Science: How the Martian Reflects Gulick's "Notes on the Theory of Organization". Administrative Theory and Praxis.39 (3):193205, DOI:10.1080/10841806.2017.1345511.

[10] Lukumayi, C., E. (2006) .The Implementation of Civil Service Reforms in Tanzania, 19912000. Master's Thesis, University of Bergen, Norway.

[11] Martin, D.W. (1987).Dejavu: French antecedents of American public administration. Public Administration Review.47 (4):297-303.

[12] Prasad, R.D., V.S.Prasad., Satyanarayana, P. \& Y.Pardharasaradhi. (2010).Administrative Thinkers. Sterling Publishers, New Delhi, India.

[13] Ranga Rao, S.P. (2012). Luther Gulick \& Lyndall Urwick.In D.R.Prasad., V.S Prasad., P.Satyanarayana. and Y.Pardhasaradhi (Eds). Administrative Thinkers, Sterling Publishers Private Ltd, New Delhi.

[14] Raadschelders, J.\& Lee, \& K.(2011).Trends in the study of public administration: Empirical and qualitative observations from public administration review, 2000-2009.Public Administration Review. (71):19-33.

[15] Simon, H. A. (1946). Proverbs of Public Administration. Public Administration Review. 6(1):53-67.

[16] Simon, H.A. (1997). Administrative Behavior. New York, NY: Free press.

[17] Stillman, R., J. (1991). Preface to Public Administration. New York, NY: St.Martin's.

[18] Stillman, R. (2015).Foreword. In M.E. Guy \& M.M .Rubin (Eds). Public Administration evolving: From foundations to the future (pp.x-xix), New York, NY: Routledge.

[19] Tanzania Public Service College. (2018). Performance Management Systems in Tanzania, unpublished lecture notes.

[20] Taylor, F.W. (1903). Shop management (No.1003).Philadelphia, PA: American Society of Mechanical Engineers.

[21] The Public Service Act, No.8, 2002.

[22] Urwick, L. (1937).Organization as technical problem. In L. Gulick and Urwick (Eds.). Papers on the Science of Administration (pp.47-88). New York, NY: Institute of Public Administration.

[23] Urwick, L. (1947).The Elements of Administration. London, Sir Issac Pitman and Sons Ltd, $2^{\text {nd }}$ edition.

[24] United Republic of Tanzania .2001. Public Service Reform Programme 2000 - 2011. Dar es Salaam.

[25] United Republic of Tanzania. (1999). Public Service Employment and Management Policy. Mkuki na Nyota Publishers, Dar es Salaam.

[26] Van der Waldt, G. (2017). Theories for research in Public Administration. African Journal of Public Affairs.9 (9):183-202

[27] Van Riper, P. P. (1998). Luther Gulick, Public Administration and Classical Management. International Journal of Public Administration. 21 (2):187-233

[28] Young, K. (2015). From administration to management. In M.E.Guy \& M.M.Rubin (Eds.). Public Administration evolving: From foundations to the future (pp.103-122), New York, NY: Rutledge. 